\title{
Educação popular na américa latina e a questão social: da desigualdade à resistência
}

\author{
Popular education in latin america and the social question: of \\ inequality to the resistance
}

\author{
Geraldo Antônio da Rosa* \\ Universidade de Caxias do Sul \\ Daniela Quadros da Silva** \\ Universidade de Caxias do Sul
}

Resumo Este estudo tem como temática central a educação popular no contexto latino-americano. O objetivo do trabalho é contextualizar a educação popular na América Latina evidenciando suas possíveis interfaces com a questão social em suas dimensões constitutivas: a desigualdade e também a resistência. Para alcançar tal objetivo, optou-se pela revisão bibliográfica, cabendo ressaltar que o trabalho se pauta pela perspectiva teórica histórico-crítica. Identifica-se na educação popular, emergente no contexto em foco, contribuições para a tomada de consciência e emancipação humana. Espera-se que as considerações aqui trazidas, ao não encerrarem o debate em torno da temática, possam contribuir para o estabelecimento de novas reflexões capazes de problematizar com maior propriedade nossa história e, por isso melhor compreender nosso presente e pensar nos limites e possibilidades para nosso futuro.

PALAVRAS-CHAVE: Educação popular; América Latina; Questão social.

\begin{abstract}
This study has as its central theme the popular education in the Latin American context. The objective is to contextualize the popular education in Latin America, demonstrating its possible interfaces with the social question in its constitutive dimensions: inequality and also resistance. To achieve this goal, was opted for the literature review, fitting to emphasize that the work is guided by the historical-critical theoretical perspective. Identifies in popular education, emerging in the context in focus, contributions to the awareness and human emancipation. It is expected that the considerations here brought to close the debate on the subject, can contribute to the establishment of new reflections able to discuss with our history's largest property and therefore better understand our present and think about the limits and possibilities for our future.
\end{abstract}

KEYWORDS: Popular education; Latin America; Social question. 


\section{Introdução}

Este trabalho apresenta aspectos históricos de ordem econômica, política e social concernentes ao contexto latino-americano que de certa forma nos deixam visualizar as contribuições que deram para a conformação de certos paradigmas na educação e, ao mesmo tempo, para a emergência de novas configurações educacionais.

Considera-se pertinente estabelecer um diálogo entre a educação popular, enquanto uma prática político-pedagógica emergente no continente em foco e a questão social, compreendida aqui enquanto o conjunto de desigualdades (e resistências) que se instauram com a consolidação (e permanência) do modo de produção capitalista. Também, acredita-se que estudar o contexto social, econômico e político da América Latina é olhar para nossa história de tal forma que permita um melhor entendimento dos motivos que configuraram certas práticas educacionais, as dificuldades em romper com certa cultura política subalternizante e com processos históricos que mantém latentes as desigualdades sociais e, sobretudo, a necessidade de se pensar em uma outra racionalidade educacional indo além de uma racionalidade instrumental, dentro dos parâmetros de uma racionalidade emancipatória, capaz de contemplar as particularidades de nossa realidade social, econômica, política e cultural e não reproduzir modelos/padrões internacionais.

O contexto latino americano é um cenário importante para situar a gênese dos movimentos de educação popular e, sem dúvida, identifica-se que o referencial teórico desta pode fornecer possibilidades para a tomada de consciência, emancipação e libertação, aspectos tão caros ao povo latino que clama por uma realidade que contemple suas singularidades.

O texto foi organizado da seguinte maneira: em um primeiro item apresenta-se algumas considerações contextuais referentes à América Latina. $\mathrm{Na}$ sequência buscou-se efetuar reflexões sobre a educação neste cenário, evidenciando alguns dos principais modelos de desenvolvimento educacional observados ao longo da história. Avançando, o trabalho apresenta a educação popular como movimento emergente a partir da década de 60, num período de efervescência dos movimentos sociais, sendo que desde então o embasamento teórico das práticas de educação popular ganha grandes repercussões com as formulações de Paulo Freire.

O percurso metodológico utilizado para a construção do trabalho é a revisão bibliográfica e a perspectiva teórica norteadora do estudo é a histórico-crítica.

Espera-se contribuir para, entre outros aspectos, melhor compreender e situar a emergência da educação popular nesse cenário, problematizando seu potencial de desvelamento e enfrentamento das expressões da "questão social" aqui materializadas, sem, contudo, encerrar o debate a respeito.

\section{America latina: breves considerações contextuais}

Sem a pretensão de realizar um resgate histórico mais aprofundado sobre o contexto que perpassa o cenário latino americano, a intenção é estabelecer reflexões 
que ajudem a melhor compreender, especialmente, as condições que conformaram certos paradigmas educacionais e, ao mesmo tempo criaram bases para a emergência de novas configurações na educação, ou seja, elementos que levaram ao surgimento dos movimentos de educação popular visando a instauração de uma nova racionalidade epistemológica no âmbito da América Latina.

Galeano (1983, p. 14), reflete que a América Latina é a "região das veias abertas", tendo em vista que desde seu "descobrimento" até a atualidade, tudo nela se transformou em capital europeu (mais tarde, norte americano). "A cada um dá-se uma função, sempre em benefício do desenvolvimento da metrópole estrangeira do momento". Observa-se portanto, que a o trata-se de um espaço onde há muito ocorrem práticas de exploração das riquezas em função de interesse endógenos. Dessa forma, grande parte das mazelas sociais é fruto de fatores como o processo histórico de exploração vivido e a ausência de um projeto voltado às reais necessidades de seu povo.

Prosseguindo, o autor, também alerta que, para muitos, ao analisar a história, fica evidente que a miséria da América Latina é fruto de sua derrota, tendo em vista que, inevitavelmente uns perdem, outros ganham dentro da lógica de desenvolvimento do capitalismo, nas mais diferentes épocas, concepções e espaços. Porém, há que se atentar que "os que ganharam, ganharam graças ao que nós perdemos: a história do subdesenvolvimento da América Latina integra [...] a história do desenvolvimento do capitalismo mundial. (GALEANO, 1983). Os palácios e a opulência de quem habita o norte, carrega sangue e lágrimas dos oprimidos.

Sobre a "descoberta" das terras latino americanas, cabe lembrar que

a civilização que se abateu sobre estas terras, vinda do além-mar, vivia a explosão criadora do Renascimento: a América aparecia como uma invenção a mais, incorporada, junto com a pólvora, imprensa, papel e bússola, ao efervescente nascimento da Idade Moderna. O desnível do desenvolvimento de ambos os mundos explica a relativa facilidade com que sucumbiram as civilizações nativas. (GALEANO, 1983, p. 28).

Essas formulações reforçam a ideia de que, de fato, as condições tão desiguais que por aqui se observam, comparadas à de outros locais, têm raízes nos longos processos de colonização que enriqueceram tantas nações e empobreceram os países da América Latina, além de lhes ter deixado também marcas profundas na cultura política de seu povo. Esta realidade, não se fez por acaso. Tudo isto é fruto de uma concepção de mundo que traz na sua base o pensamento europeu, que naturalizou e justificou todo processo de colonização e neocolonização na gênese da invasão da América Latina até a contemporaneidade.

Dessa forma, o juízo construído a nosso respeito, de caráter condenatório, traz reflexões importantes sobre a maneira como nós nos reconhecemos: "Somos a criança a quem se repete continuamente: 'Não prestas para nada; nunca serás nada...', e que acabará aceitando esta opinião, conformando-se com ela, desmoralizando-se, perdendo todos os estímulos. (BOMFIM, 2008, p.10). Desse modo, internaliza-se em seu povo sentimentos de inferioridade e subalternidade perante outras nações. 
Nesta mesma linha de pensamento, outro reflexo dos processos de colonização/exploração aqui experenciados incide sobre o que se chama de "subdesenvolvimento". Sobre isso, Bomfim (2008, p. 23), faz a seguinte reflexão:

Colocai um organismo em condições de vida que o dispensem de exercitar os seus órgãos sensoriais e locomotores, e estes se atrofiarão fatalmente. [...], assim, é uma consequência fatal em biologia que, tornando-se parasita, um organismo degenera, involui.

O mesmo ocorre com o que o autor já citado chama de "organismos sociais", por isso, observa-se tamanho contexto de desigualdade social na América Latina, uma vez que, os países que a compõem foram (e ainda o são?) perversamente explorados. Esta nefasta exploração a que fomos submetidos encontra-se presente de forma palpável em nossa estruturação econômica, social, política e cultural.

Outro fator que merece ser abordado prende-se a uma conjuntura histórica marcada pela centralização do poder e dos interesses. Silva (2010) leva à reflexão de que a formulação e conformação dos nossos hábitos e crenças são heranças de uma sociedade que passou por longos processos históricos de colonização, a qual ainda hoje está centrada no patrimonialismo. Analisando especificamente os resquícios desse processo colonizador na garantia de direitos de cidadania no Brasil, por parte do Estado, a autora aponta que a herança conservadora que temos contribui para uma cultura política "do não direito" com forte viés patrimonialista e privatista. (SILVA, 2010, p. 13). Portanto, todo o cenário de corrupção da máquina pública e a ausência de políticas públicas voltadas a inclusão encontram grande parte das explicações em aspectos culturais e no processo de estruturação a que fomos submetidos ao longo de nossa história.

Além das questões de ordem identitária, do povo latino-americano e do ideário que conforma a formulação de respostas estatais às problemáticas por ele enfrentadas cotidianamente, considera-se de igual relevância problematizar rupturas e permanências observadas no âmbito educacional.

Neste sentido, concorda-se com Moretti (2008) quando esta defende que não é possível dizer que há uma pedagogia latino-americana única e sistematizada, mas sim que existem diversas pedagogias inscritas nos movimentos sociais e populares cujas motivações vinculam-se a uma perspectiva de transformação do mundo. O que nós temos, portanto, seria uma pedagogia com um viés predominantemente revolucionário. Nesse sentido, a partir da conjuntura observada na América Latina, a autora reforça que os movimentos sociais são espaços importantes para se pensar na consolidação desta Pedagogia Revolucionária emergente.

Por sua vez, Streck (et. al. 2014, p. 34) alerta que

ainda que na América Latina tenha se cumprido um programa em educação sob o domínio do neoliberalismo, a história segue tendo um peso importante na 'recuperação da dignidade política e social (PUIGRRÓS, 2014, p. 103) e para a educação libertadora no continente. 
Tendo em vista os aspectos até aqui abordado se quer problematizar, na sequência, quais repercussões podem ser observadas, a partir dos aspectos sociais advindos em grande parte dos processos de colonização vividos no contexto latino americano, anteriormente apresentados, nas concepções e práticas de educação contemporâneas na América Latina. Indaga-se, entre outras questões, sobre as seguintes: existe um pensamento genuinamente latino-americano, nos processos e projetos educacionais em diferentes níveis de ensino e espaços educativos? As políticas educacionais são construídas de maneira democrática ou trazem marcas das influências dos organismos internacionais ainda na contemporaneidade?

\section{Educação no cenário latino-americano}

A discussão sobre educação na América Latina é interpelada, em muito, por aspectos políticos, tanto no sentido dos governos atuantes como no que tange à mobilização da sociedade civil. Para Sander (2008), a história da educação latino-americana foi, em grande parte, influenciada pelo pensamento sociológico em curso na América Latina, desde o século XX.

Ballestrim (2013) traz para o debate o pós-colonialismo, tido enquanto um percursor para o argumento fundante do pensamento pós-colonial. Este teria sido, conforme a autora, radicalizado pelo Grupo Modernidade/Colonialidade (M/C) ${ }^{1}$, formado no final dos anos de 1990 por diversos intelectuais latino-americanos. A importância desta contextualização para o debate em torno da educação na América Latina reside no fato de que este coletivo teria realizado um movimento epistemológico muito relevante para a renovação crítica e até mesmo utópica das ciências sociais a partir dos meados do século XX. Tal movimento implementa a discussão sobre o póscolonialismo através da noção de "giro decolonial. (BALLESTRIN, 2013).

O pós-colonialismo remete a dois entendimentos. Um deles seria o de que trata-se de um período histórico posterior aos processos de descolonização, referindo-se, portanto, à independência, à libertação e emancipação das sociedades que até então eram exploradas. Um outro entendimento faz uso do termo para referir-se a um conjunto de referenciais teóricos frutos de estudos literários e culturais que passam a ganhar evidência em meados dos anos 80 em instituições universitárias dos Estados Unidos e também da Inglaterra. Convém ressaltar também que quando se fala em póscolonialismo nos remetemos, em termos espaciais, às realidades do continente africano e asiático, enquanto na América Latina, passa-se a vivenciar os processos da Pedagogia da Libertação, Filosofia da Libertação e da Teologia da Libertação. Estes movimentos, na contemporaneidade, passam a fazer parte de um movimento tido como descolonial.

Recorrendo à Costa (2006, p. 83-84 apud BALLESTRIN, 2013, p. 90) é possível associar que a palavra "colonial", presente no termo, diz respeito às situações de opressão, mesmo que elas não necessariamente sejam causa exclusiva do colonialismo, embora saiba-se que o mesmo reforça ou reproduz tais situações.

Entre outras concepções do que, de fato, trata o termo em questão, está a compreensão de que ele sugere a relação antagônica entre colonizado e colonizador. Dessa maneira, 
Mesmo que não linear, disciplinado e articulado, o argumento póscolonial em toda sua amplitude histórica, temporal, geográfica e disciplinar percebeu a diferença colonial e intercedeu pelo colonizado. Em essência, foi e é um argumento comprometido com a superação das relações de colonização, colonialismo e colonialidade. (BALLESTRIN, 2013, p. 91).

Em síntese, observa-se que as discussões emergentes no âmbito do Grupo Modernidade/Colonialidade dialogam com a ideia de que tornava-se cada vez mais necessário estabelecer um pensamento capaz de contemplar as especificidades da realidade social, econômica e cultural da América Latina, considerando que "a elaboração intelectual do processo de modernidade produziu uma perspectiva de conhecimento e um modo de produzir conhecimento que demonstram o caráter do padrão mundial de poder: colonial/moderno, capitalista e eurocentrado." (QUIJANO, 2005, p. 9 apud BALLESTRIN, 2013, p. 104).

Considera-se pertinente destacar os modelos educacionais evidenciados no decorrer do desenvolvimento histórico da América Latina. Por meio desse breve resgate das principais ideias que compõem os modelos em termos de educação, é possível também compreender o desenvolvimento das próprias sociedades latino-americanas, haja vista a interlocução necessária entre educação e sociedade.

A partir do estudo de Weinberg (1987), identifica-se como um primeiro modelo, a ilustração, sendo esse prévio à independência. Como principal característica está seu caráter modernizador, demandando da educação uma instrução voltada, predominantemente, para as classes dirigentes. Já o modelo seguinte se alastra em um momento histórico onde se criam as bases condutoras da independência. Trata-se do modelo de emancipação, que incorpora na classe dirigente princípios deslocadores do ideal político de "súdito fiel" para o de "cidadão ativo" (WEINBERG, 1987, p. 26), remetendo à ideia de liberdade, igualdade e justiça.

$\mathrm{O}$ autor contextualiza que o período de ascensão dos movimentos independentistas foi marcado pelas lutas armadas que visavam consolidar a emancipação e pelos próprios danos ocasionados pelas guerras civis. Nesse contexto, o modelo mais democrático fica ameaçado sendo exigido, em contrário, um modelo mais autoritário que possa contribuir para a construção e a consolidação de um Estado cujo exercício da força lhe seja legitimado. Assim, ganha espaço o modelo educacional vinculado aos liberais e conservadores. Estes acreditam que têm a capacidade de reestabelecer a ordem.

Embora a maior parte da população latino-americana pertencia às áreas rurais, nem os liberais, tampouco os conservadores se importavam com as questões educacionais dessa população. Essa ausência em termos de políticas educacionais específicas resultou numa demora significativa para incorporar o segmento rural na economia e na sociedade moderna que estava se desenvolvendo, bem como dificultou a obtenção de maior participação política. (WEINBERG, 1987).

Nesse sentido, no intuito de incorporar um maior número de pessoas àquilo que entendia-se como civilização, surgem novas preocupações no que se refere à educação. 
Para integrar os países parecia um pré-requisito superar o isolamento, a miséria, a fragmentação linguística, dotá-los enfim de instituições e legislações modernas e estáveis. Tudo isso, sempre conforme a opinião de alguns os homens mais distinguidos daquela geração, requeria políticas educacionais a longo prazo [...] (WEINBERG, 1987, p. 31).

A educação ganha contornos de função política, econômica e social. As propostas de educação popular passam a ganhar destaque e voltavam-se para a criação de uma nova sociedade. Expoente importante da educação popular, José Pedro Varela considerava, inclusive, esta educação como potente para a transformação da sociedade latino-americana, contudo, como lembra Weinberg (1987), a ideologia predominante em seu pensamento converte-se, paulatinamente, em positivismo.

O positivismo é o modelo que serve para se pensar a América Latina num contexto de interesse pelo progresso. No período de efervescência da Revolução Industrial, "a América necessitava de ordem política e de liberdade econômica, as quais uma vez obtidas, lhe dariam, como num passe de mágica, o progresso [...]. O positivismo the ofereceria a chave. (WEINBERG, 1987, p. 37).

Os modelos educacionais que se evidenciam no decorrer da história da América Latina permitem dizer que muitas foram as transformações societárias por aqui ocorridas e que a educação sempre acompanha essas mudanças, variando suas funções conforme interesses de ordem econômica, social, política e cultural.

Considera-se pertinente ressaltar as fortes influências de padrões oriundos de organismos internacionais na proposição de caminhos e na avaliação da educação dos países latino americanos. Segundo Boron (2003 apud LANDINI; PEREIRA, 2016), aliado ao neoliberalismo, órgãos como o Banco Mundial e o Fundo Monetário Internacional protagonizam uma série de mudanças, nas últimas décadas do século $\mathrm{XX}$, especialmente no âmbito educacional, onde evidencia-se a educação como um serviço, um bem de consumo destinado a um fim, qual seja, formar indivíduos para o "mundo do trabalho". Verifica-se portanto, uma educação voltada aos interesses mercadológicos, sendo que as políticas públicas, bem como todo processo de regulação cumpre rigorosamente este ideário.

Especialmente com o advento do neoliberalismo, o fator econômico prevalece e a educação mantém o processo de fragmentação dentro da lógica dos processos de produção. Dessa forma, os sujeitos têm sua compreensão de mundo comprometida, tendo em vista que o capitalismo condiciona a ver somente o que é mais aparente e não a essência dos fenômenos. Nesse contexto, "a real condição do indivíduo é subsumida à exploração e à lógica de acumulação do capital. Assim, o que se apresenta aos indivíduos singulares é uma realidade parcial que, por meio de mecanismos ideológicos sugere uma realidade harmônica, equilibrada e neutra [...]" (LANDINI; PEREIRA, 2016, p. 144).

Como visto anteriormente, a Educação Popular foi um dos modelos educacionais instaurados na América Latina. Certamente, muitas contradições, limites e possibilidades se colocam no debate sobre sua concepção e materialização através de 
práticas verdadeiramente comprometidas com a emancipação dos sujeitos, mas há que se ter em vista a crença de que

por baixo das cinzas que encobrem uma grande parte de nossa história pedagógica na América Latina, há brasas. Esse fogo é importante para enraizar a educação popular com vista à reconstrução de uma esfera pública na qual haja tanto condições de cada cidadão e cada cidadã dizer a sua palavra quanto o sentimento de pertença a um mundo que tem a sua permanência construída coletivamente (STRECK, 2006, p. 277).

A seguir, problematiza-se algumas potencialidades evidenciadas pela via da educação popular no que diz respeito à contribuição desta para a construção de uma nova ordem societária no âmbito da América Latina tendo em vista as alternativas que ela oferece, enquanto prática político-pedagógica, no reconhecimento crítico acerca dos processos que geraram desigualdades sociais tão latentes e também para permitir a criação coletiva de mecanismos possíveis para fazer frente às mesmas. Dito de outro modo, quer se problematizar as potencialidades da educação popular, enquanto campo de conhecimento e prática educativa para reconhecer a "questão social" em suas múltiplas expressões e as elas resistir e se opor.

\section{Emergência da educação popular na américa latina: da desigualdade à resistência}

Primeiramente, há que se ter clareza do conceito de questão social. Entende-se que ela diz respeito a um conjunto de desigualdades sociais inerentes à sociedade capitalista cuja gênese está na relação conflituosa entre capital e trabalho (IAMAMOTO, 2001).

Iamamoto explica também que a questão social expressa-se através de “[...] desigualdades econômicas, políticas e culturais das classes sociais, mediatizadas por disparidades nas relações de gênero, características ético-raciais e formações regionais, colocando em causa amplos segmentos da sociedade civil no acesso aos bens da civilização" (Idem, p. 17). Sendo desigualdade, ela é também resistência e rebeldia, pois como enfatiza Pereira (2001), ela só passa a ser politicamente reconhecida devido à sua publicização por atores que fizeram pressão para incorporar neste cenário os problemas sociais emergentes. Diante disso, cabe a reflexão: "Tudo nos é proibido, a não ser cruzarmos os braços? A pobreza não está escrita nos astros: o subdesenvolvimento não é fruto de um obscuro desígnio de Deus. As classes dominantes põem as barbas de molho, e ao mesmo tempo anunciam o inferno para todos." (GALEANO, 1983, p. 19).

É pertinente ressaltar que deseja-se evitar cair em messianismos no sentido de colocar a educação, em especial a educação popular, como única responsável pela transformação social. É sabido que a educação, de forma geral, sofre impactos severos da lógica perversa do capital, cada vez mais dominante, porém, como lembra Freire (2013, p. 96), é necessário compreender a educação sempre como uma "forma de intervenção no mundo" que "implica tanto o esforço de reprodução da ideologia dominante quanto o seu desmascaramento", ou seja, apesar de ser condicionada, em muito, por uma ideologia dominante, ela pode encontrar brechas para, através de prá- 
ticas de cunho emancipatório e problematizador da realidade vigente, ir ao encontro dos interesses da classe trabalhadora.

O contexto latino-americano é o espaço de surgimento da educação popular, tendo em vista o fervor das lutas populares por aqui emergentes, especialmente em meados da década de 60. Assim,

\begin{abstract}
a concepção de Educação Popular (EP) como campo de conhecimento e como prática educativa se constituiu em exercício permanente de crítica ao sistema societário vigente, assim como de contra-hegemonia ao padrão de sociabilidade por ele difundida. Construída nos processos de luta e resistência das classes populares, é formulada e vivida, na América Latina, enquanto uma concepção educativa que vincula explicitamente a educação e a política, na busca de contribuir para a construção de processos de resistência e para a emancipação humana, o que requer uma ordem societária que não seja a regida pelo capital. (PALUDO, 2015, p. 220).
\end{abstract}

É imprescindível citar Paulo Freire como um grande expoente no âmbito da educação popular. O trabalho por ele desenvolvido em diversos países (não somente na América Latina), partia do pressuposto de que a educação não é neutra. A Educação Popular, na ótica de Freire, é popular pelo potencial de organização da classe trabalhadora. A sua teoria é incorporada por educadores, militantes e trabalhadores dos movimentos populares, usada para embasar suas práticas educativas. (MACIEL, 2011).

Conforme lembra Gohn (2002), ainda na atualidade, Freire é referência nas reformulações de educação popular com destaque para a cultura e a dialogicidade do ato educativo. A mesma autora sinaliza que a partir dos anos 90 , impõe-se à educação popular, na América Latina, um rever de suas práticas, metodologias e de seus conceitos. A autora cita o Congresso Internacional de Americanistas realizado em julho de 1988 na Holanda com o tema "Educação Popular na América Latina", reunindo diferentes segmentos sociais como um importante momento de balanço das experiências até então realizadas. Nas palavras dela,

diagnosticou-se a necessidade de mudanças, mas também se destacou a importância da EP como espaço educativo da sociedade civil, sua presença como instrumento de organização, formação e desenvolvimento da consciência social junto a inúmeros movimentos populares que lutaram pela transformação de regimes políticos autoritários, liderados por militares ou caudilhos locais. (GOHN, 2002, p. 53).

A educação popular na América Latina ocupa importante papel dentro dos movimentos populares, desenvolvendo-se conectada às dinâmicas desses movimentos. Suas ações educativas devem se realizar a partir da realidade dos sujeitos com os quais se está trabalhando e são estes sujeitos (políticos) que se constituem como protagonistas da transformação. Nisso reside a vinculação da educação popular com as organizações e mobilizações sociais. (HUIDOBRO, 1985).

Resgatando as ideias de Freire (2014) sobre sujeitos e processos de opressão, pode-se salientar que são justamente os oprimidos, aqueles capazes de entender o real 
sentido de uma sociedade opressora e a necessidade de sua libertação. Na obra citada, Fiori sintetiza uma complexa questão

$$
\begin{aligned}
& \text { em regime de dominação de consciências, em que os que mais } \\
& \text { trabalham menos podem dizer a sua palavra e em que multidões } \\
& \text { imensas nem sequer têm condiçôes para trabalhar, os dominadores } \\
& \text { mantêm o monopólio da palavra, com que mistificam, massificam e } \\
& \text { dominam. Nessa situação, os dominados, para dizerem sua palavra, } \\
& \text { têm que lutar para toma-la. Aprender a toma-la dos que a detêm e } \\
& \text { a recusam aos demais é um difícil, mas imprescindível aprendizado } \\
& \text { - é a 'pedagogia do oprimido' (FIORI, 2014, p. 30). }
\end{aligned}
$$

Nesse sentido, é possível inferir que a Educação Popular permanece, na cena contemporânea, reinventando-se, mas mantendo a característica de servir como importante base de sustentação de práticas contra hegemônicas (VARGAS, 2014) e que ela contribui com a “(...) apropriação de uma teoria crítica da sociedade e da prática política que permita avançar na apreensão dos fundamentos concretos da vida social"(IAMAMOTO, 2008, p. 414 apud VARGAS, 2014, p. 112). Portanto, enquanto prática política e pedagógica emancipadora, como a defini Carrilo (2013), a educação popular pode ser uma alternativa, especialmente no contexto latino americano, para desvendar as expressões da "questão social" e a elas resistir.

Com isso também é possível dizer que a educação popular já ocupou e ainda ocupa, na contemporaneidade, papel importante no contexto latino-americano. $\mathrm{O}$ referencial teórico de seus pressupostos aponta para potencialidades no que tange à construção de um modelo educacional que aproxime o povo latino-americano de sua verdadeira história, reconheça-se nela e promova rupturas com resquícios advindos da herança conservadora e subalternizante e das mais distintas desigualdades sociais e educacionais que países colonizadores aqui deixaram.

\section{Considerações finais}

O estudo ora apresentado propôs uma discussão sobre a educação popular no contexto latino-americano. Evidenciou-se, num primeiro momento, alguns aspectos históricos de ordem econômica, social, política e cultural que podem ter contribuído para a conformação da cultura política que aqui predomina, conformadora de certa identidade social, além da consolidação de alguns paradigmas educacionais importantes. Um outro item discorreu, especificamente, sobre a educação no cenário latino-americano para, na sequência, abordar a emergência da educação popular neste cenário, explorando a gênese de suas práticas, seus limites e potencialidades.

As formulações até aqui expostas possibilitam inferir que a América Latina tem como grande desafio repensar sua história e os modelos de educação vigentes para compreender, de fato, os processos histórico-estruturais que conformaram o subdesenvolvimento dos países latino-americanos.

Nesse sentido, a educação popular pode, através dos pressupostos teóricos que a norteiam, contribuir como possibilidade de apreensão crítica dessa realidade, das latentes desigualdades sociais que aqui se vivenciam, bem como pode oferecer alternativas de resistência. Apresenta, portanto, muitas interfaces com a "questão social". 
É importante retomar que com isso, não se está colocando a educação como única responsável pela transformação social, visto que ela está inserida na lógica do capital e por ela é influenciada constantemente. Assim, parafraseando Freire, a educação não pode mudar o mundo. Mas ela muda as pessoas e as pessoas, sim, podem mudar o mundo. Portanto, evidencia-se que

\begin{abstract}
A imposição colonial-moderna silenciou culturas e pedagogias. Mesmo que exista a recusa em reconhecer, por parte de quem domina a cultura e os direitos dos povos campesinos indígenas, por exemplo, os métodos criativos e alternativos próprios de sua sobrevivência e de sua resistência, estes têm sido a outra parte da realidade feita na/da experiência educativa (STRECK, et. al, 2014, p. 38).
\end{abstract}

Concorda-se com Yazbek (2009, p. 127) no aspecto por ela tratado que diz respeito ao fato de que "o mesmo movimento que cria as condições para a reprodução da sociedade de classes, cria e recria os conflitos resultantes dessa relação e as possibilidades de sua superação". Assim, a América Latina, lugar de tantas mazelas materializadas na vida cotidiana de seu povo é também lugar de produção de saberes e práticas potentes, emergentes desse povo, para e com ele, capazes de afirmar seu pertencimento e oferecer alternativas de torná-los sujeitos de suas próprias histórias numa perspectiva de transformação social.

\title{
Referências
}

BALLESTRIN, L. América Latina e o giro decolonial. Revista Brasileira de Ciência Política. no 11. Brasília, maio - agosto de 2013. Disponível em: <http://www.scielo.br/pdf/rbcpol/ n11/04.pdf>. Acesso em: 08 set. 2016.

BOMFIM, M. A América latina: males de origem [online]. Rio de Janeiro: Centro Edelstein de Pesquisas Sociais, 2008. Disponível em: <http://books.scielo.org>. Acesso em: 14 jul. 2016.

CARRILO, A. T. A educação popular como prática política e pedagógica emancipadora. In: STRECK, D. R; STEBAN, M. T. (Orgs). Educação popular: lugar de construção social coletiva. Petrópolis, Rio de Janeiro: Vozes, 2013.

FIORI, E. M. Aprender a dizer a sua palavra (prefácio) In: FREIRE, P. Pedagogia do oprimido. 57 ed., Rio de Janeiro: Paz e Terra, 2014.

FREIRE, P. Pedagogia do oprimido. 57ed. Rio de Janeiro: Paz e Terra, 2014.

FREIRE, P. Pedagogia da autonomia. 46 ed. Rio de Janeiro: Paz e Terra, 2013.

GALEANO, E. As veias abertas da América Latina. 15 ed. Rio de Janeiro: Paz e Terra, 1983.

GOHN, M. G. Educação popular na América Latina no novo milênio: impactos do novo paradigma. ETD: Educação Temática Digital. v. 4. n. 1. Campinas, 2002. Disponível em:<http:// ojs.fe.unicamp.br/ged/etd/article/view/1802/1644>. Acesso em 16 jul. 2016. Disponível em:< http://www.ssoar.info/ssoar/bitstream/handle/document/10497/ssoar-etd-2002-1-gohn-educacao_popular_na_america_latina.pdf?sequence=1> Acesso em 09 set. 2016.

HUIDOBRO, J. E. G. En torno del sentido político de la educación popular. In: MADEIRA, F.R.; MELLO, G. N. América Latina - os modelos teóricos e a realidade social. São Paulo: Cortez, 1985.

IAMAMOTO, M. V. A Questão Social no Capitalismo. In: Temporalis/Associação Brasileira de Ensino e Pesquisa em Serviço Social. Ano 2, n. 3, (Jan/Jul. 2001). Brasília: ABEPSS, Graflini, 2001. 
LANDINI, S. R.; PEREIRA, G. A. M. Avaliações internacionais da educação e suas bases onto epistemológicas: o caso da pesquisa TALIS. In: TROJAN, R.; BATISTA, C. M. S. Políticas Educacionais e Internacionais: perspectivas para educação comparada. Curitiba: CRV, 2016.

MACIEL, K. F. O pensamento de Paulo Freire na trajetória da educação popular. Educação em Perspectiva. Viçosa, v. 2, n. 2, jul./dez. 2011. Disponível em: <http://www.seer.ufv.br/seer/ educacaoemperspectiva/index.php/ppgeufv/article/viewFile/196/70>. Acesso em: 09 set. 2016.

MORETTI, C. Z. A educação popular em José Martí e no movimento indígena de Chiapas: a insurgência como princípio educativo da pedagogia Latino-Americana. (Dissertação de mestrado). São Leopoldo: UNISSINOS, 2008.

PALUDO, C. Educação popular como resistência e emancipação humana. Cad. Cedes, Campinas, v. 35, n. 96, p. 219-238, maio/agosto. 2015. Disponível em:< http://www.scielo.br/pdf/ ccedes/v35n96/1678-7110-ccedes-35-96-00219.pdf >. Acesso em: 08 set. 2016.

PEREIRA. P. A. P. Questão Social, Serviço Social e Direitos de Cidadania. In: Temporalis/ Associação Brasileira de Ensino e Pesquisa em Serviço Social. Ano 2, n. 3, (Jan/Jul.2001). Brasília: ABEPSS, Graflini, 2001.

SANDER, B. Educação na América Latina: Identidade e globalização. Educação, Porto Alegre, v. 31, n. 2, p. 157-165, maio/ago 2008. Disponível em: <http://revistaseletronicas.pucrs.br/teo/ ojs/index.php/faced/article/view/2766/2113>. Acesso em: 24 abr. 2017.

SILVA, V. A Política Pública de Assistência Social: veiculadora de direitos ou ainda reiteradora da subalternidade? (Monografia de conclusão de curso). Caxias do Sul: UCS, 2010.

STRECK, D. R. et al. Educação Popular e Docência. São Paulo: Cortez, 2014.

A educação popular e a (re) construção do público. Há fogo sob as brasas? Revista Brasileira de Educação v. 11 n. 32 maio/ago. 2006. Disponível em: <http://www.scielo.br/pdf/ rbedu/v11n32/a06v11n32.pdf>. Acesso em: 08 set. 2016.

VARGAS, Tatiane Moreira de. Serviço Social e Educação Popular: caminhos que se cruzam na direção de processos emancipatórios. (Tese de doutorado). Porto Alegre: PUC/RS, 2014.

WEINBERG, G. Modelos educacionais no desenvolvimento histórico da América Latina. In: SAVIANI, Dermeval. et al. Desenvolvimento e Educação na América Latina. 5 ed. São Paulo: Cortez, 1987.

YAZBEK, M. C. O Significado Sócio-Histórico da Profissão. In: CFESS (Conselho Federal de Serviço Social) /ABEPSS (Associação Brasileira de Ensino e Pesquisa em Serviço Social). Serviço Social: direitos sociais e competências profissionais. Brasília: CFESS/ABEPSS, 2009.

\section{Notas}

\footnotetext{
${ }^{1}$ Com Escobar (2003 apud BALLESTRIN, 2013) pode-se citar enquanto elementos teóricos balizadores deste grupo a Teologia da Libertação, além de debates na filosofia e ciência social latino-americana e debates sobre modernidade e pós modernidade na América Latina. Como principal orientador está a reflexão constante acerca da realidade política e cultural que perpassa o cenário latino-americano, com ênfase no conhecimento subalternizado dos segmentos explorados e oprimidos. Entre alguns atores importantes nesse coletivo está Dussel e Darcy Ribeiro.
}

* Professor doutor da Universidade de Caxias do Sul, Caxias do Sul, Rio Grande do Sul. Brasil.

** Mestranda em Educação pela Universidade de Caxias do Sul, Caxias do Sul, Rio Grande do Sul. Brasil 
Educação popular na américa latina e a questão social: da desigualdade à resistência

\section{Correspondência}

Daniela Quadros da Silva - Universidade de Caxias do Sul. Rua Francisco Getúlio Vargas, 1130. CEP: 95070560. Caxias do Sul, Rio Grande do Sul, Brasil.

E-mail: garosa6@ucs.br-dqsilva@ucs.br

Recebido em 23 de setembro de 2016

Aprovado em 11 de outubro de 2016 
